\title{
As agências reguladoras independentes e o Tribunal de Contas da União: conflito de jurisdições?*
}

\author{
Eduardo Granha Magalliães Gomes**
}

S U MÁRIO: 1. Introdução; 2. O Estado regulador; 3. A responsabilização das agências; 4. Agências e TCU: conflito institucional?

SuMMARY: 1. Introduction; 2 . The regulatory state; 3 . Agency accountability; 4. Agencies and the Federal Court of Accounts: institutional conflict?

PalAVRAS-CHAVE : regulação; agência reguladora independente; accountability; Tribunal de Contas da União; instituição; auditoria de desempenho; gestão por resultados.

KEY WORD S : regulation; independent regulatory agency; accountability; Federal Court of Accounts; institution; performance audit; results management.

Este artigo analisa a emergência, no Brasil, de agências reguladoras independentes (ARIs) e suas especificidades quanto ao desenho institucional; analisa ainda a evolução recente da atuação do Tribunal de Contas da União (TCU) no contexto da nova gestão pública. No desenho das ARIs têm destaque os mecanismos que lhes conferem independência política, dada a natureza de suas atribuições e competências. Por outro lado, o TCU vem ampliando seu campo de atuação, passando a avaliar não mais apenas os aspectos formais da legalidade de procedimentos, mas também o desempenho e resultados alcançados por órgãos e entidades públicas. O TCU passa a atuar no acompanhamento e avaliação do desempenho das agências. $\mathrm{O}$ artigo analisa a interface entre independência e controle, discutindo possíveis conflitos institucionais entre as agências reguladoras e o TCU.

* Artigo recebido em fev. e aceito em maio 2006.

** Doutorando e mestre em administração pública e governo pela Eaesp/FGV, graduado em administração e engenharia metalúrgica. Endereço: Rua Pio Porto de Menezes, 120, ap. 501-B — Luxemburgo - CEP 30380-300, Belo Horizonte, MG, Brasil. E-mail: edgranha@uol.com.br. 
The independent regulatory agencies and the Federal Court of Accounts: a jurisdictional conflict?

This article analyzes the emergence of the independent regulatory agencies (IRAs) in Brazil and their specificities as to their institutional design. It also discusses the recent developments in the Federal Court of Accounts' actions within the new public management context. IRAs were designed with emphasis on the features that give them political independence, considering the nature of their attributions and capabilities. On the other hand, the Federal Court of Accounts (FCA) has broadened its area of activities, assessing not only the formal aspects of the legality of procedures, but also the performance and the results of organisms and public institutions. The FCA is tracking and assessing the agencies' performance. The article analyzes the interface between independence and control, discussing possible institutional conflicts between regulatory agencies and the FCA.

\section{Introdução}

O modelo de regulação por meio de agências reguladoras independentes, que sucedeu a privatização das estatais prestadoras de serviços públicos no Brasil, previu determinadas características institucionais aos entes reguladores, particularmente independência política e especialização técnica, visando prover um ambiente propício à atração de investimentos. Simultaneamente o Tribunal de Contas da União, na esteira do novo paradigma introduzido pela nova gestão pública, ampliou seu escopo de atuação além das tradicionais auditorias de regularidade, passando a fazer avaliações de resultados ou de desempenho, inclusive dos mercados então privatizados. Neste artigo discute-se o conteúdo dessas duas reformulações institucionais e em que medida presencia-se um conflito de jurisdições.

\section{O Estado regulador}

A partir da década de 1970, devido principalmente às crises econômicas e também à presença de ambientes político e acadêmico propícios, vários países iniciam mudanças importantes no modo de intervenção do Estado na economia: o "Estado produtor" cede lugar ao "Estado regulador" em importantes setores econômicos e sociais. ${ }^{1}$

\footnotetext{
${ }^{1}$ A rigor, a recomendação prevalecente no ambiente acadêmico era de redução do Estado ao mínimo, transferindo ao mercado econômico boa parte de suas atribuições, corrente identificada com o neoliberalismo. Na prática, o Estado manteve, ou mesmo aumentou, o gasto público, apesar da "radical" alteração na sua forma de intervenção (Abrucio, 2000).
} 
Particularmente no Brasil, tal mudança ocorre um pouco mais tarde, a partir dos anos 1990, mas deriva de condicionantes semelhantes observados em outros países. Conforme Bresser-Pereira (1996), o Estado brasileiro encontrava-se inserido em um ambiente de crise do Estado, revelada em quatro dimensões: crise fiscal, devido à falta de crédito e de poupança interna; crise do modo de intervenção, com a crítica ao modelo de Estado positivo; crise política; e, finalmente, crise administrativa, referente ao modelo burocrático de gestão. A crise do modo de intervenção foi abordada, principalmente a partir do governo Collor (1990-92) e mais tarde no governo Fernando Henrique Cardoso (1995-2002), por meio da privatização abrangente de empresas estatais responsáveis pela produção de bens e serviços, como siderurgia, mineração, telefonia, energia elétrica, entre outras. ${ }^{2}$

As justificativas para a privatização das empresas estatais, principalmente das prestadoras de serviços públicos, encontram-se na baixa capacidade de investimento do Estado em crise, investimentos fundamentais para a competitividade das empresas nacionais (antes protegidas) diante de um ambiente globalizado, bem como para o atendimento às demandas crescentes da população; nas disfunções da cultura burocrática inerente ao setor público, que também contribuíam para uma menor competitividade das estatais; e na excessiva ingerência política sobre elas, o que limita a ocupação meritocrática dos postos de direção e distorce o próprio mercado. Como observa Marques Neto (2003:10-11), a respeito da definição das tarifas públicas,

a majoração ou minoração de preços podia ser determinada, diretamente, pela vontade política do governante, pautada por razões de ordem monetária (conter a inflação), fiscal (aumentar a rentabilidade da estatal para viabilizar o ingresso de recursos no tesouro mediante pagamento de dividendos ou operações creditícias), eleitoral (agradar o eleitor em períodos de disputa política), social (ampliar a fruição de uma utilidade pública essencial) ou mesmo econômica (desincentivar o consumo ou favorecer o desenvolvimento de um setor que dependesse do bem ou serviço como insumo).

Ou seja, a privatização das empresas estatais aparece como solução para uma série de incapacidades e distorções presentes na forma de atuação do Estado.

\footnotetext{
2 Ressalte-se que a Petrobras foi mantida em poder do Estado, dado seu caráter estratégico, embora seu monopólio tenha sido flexibilizado.
} 
No entanto, a privatização não representa, necessariamente, a ausência do Estado na provisão dos serviços. Como observa Majone (1999:10) ao justificar a existência anterior das empresas estatais, alguns setores de serviços públicos, como gás, eletricidade, água ou telefone, são monopólios naturais e são considerados estrategicamente importantes. "Daí supunha-se que a propriedade estatal daria ao Estado o poder para impor uma estrutura planejada à economia, e ao mesmo tempo proteger o interesse público contra interesses privados poderosos." Enfim, privatizados ou não, o fato é que tais serviços continuam sendo fundamentais, tanto no tocante ao desenvolvimento econômico, quanto no atendimento a demandas públicas redistributivas ou de bem-estar social. Além disso, o próprio mercado apresenta falhas, não prescindindo, assim, de instituições destinadas a mitigá-las. Ou seja, ainda que abrindo mão da produção direta desses bens e serviços, o Estado assume a função essencial de regular os mercados privados que os produzem, visando ao interesse público e ao bom funcionamento do próprio mercado.

\section{As agências reguladoras independentes (ARIs)}

A mudança da forma direta de intervenção do Estado levou então, em muitos países, à criação ou reforço de órgãos altamente especializados com a missão, bastante complexa, de regular os mercados ora privatizados. ${ }^{3}$ No caso do Brasil, são criadas as agências reguladoras independentes (ARIs), no contexto das privatizações, tendo como pioneiras a Agência Nacional de Energia Elétrica (Aneel) e a Agência Nacional de Telecomunicações (Anatel), criadas em 1997. Basicamente, "as agências são autarquias sob regime especial, parte da administração pública indireta, e caracterizadas por independência administrativa, estabilidade de seus dirigentes, autonomia financeira e ausência de subordinação hierárquica" (Melo, 2001).

A literatura aponta algumas hipóteses explicativas para a origem desse modelo de órgãos reguladores. A primeira delas refere-se a um certo "isomorfismo institucional" que sugere, no caso brasileiro, a importação de formatos institucionais presentes nos processos similares de reforma liberalizante ocorridos em outros países, seja por uma simples questão de modismo seja pela indução dos órgãos financiadores.

\footnotetext{
${ }^{3}$ Houve também a criação de agências reguladoras para controle de mercados privados já estabelecidos, como dos planos de saúde: Agência Nacional de Saúde (ANS). 
Uma outra explicação remete à chamada "transferência de culpa", ou "blame shifting", na qual o Executivo e o Legislativo transferem a responsabilidade pela eventual tomada de decisões às novas entidades independentes. Essa transferência ou delegação seria politicamente conveniente, seja pelo conteúdo impopular seja pelo tecnicismo excessivo das avaliações e decisões envolvidas. Ou seja, em uma análise de custo-benefício, os ganhos políticos que os governantes poderiam auferir ao tomar tais decisões seriam inferiores aos custos políticos envolvidos em decisões técnicas eventualmente equivocadas ou impopulares, referentes a temas sensíveis como aumento de tarifas públicas (Melo, 2001:251).

No entanto, a explicação que interessa neste artigo refere-se à redução do risco regulatório para os investidores dos processos de privatização. Como observa Marques Neto (2003:9), no modelo de intervenção anterior, o caráter de interesse público relacionado aos bens e serviços em questão "justificava" uma atuação extremamente discricionária das empresas estatais no mercado e a subjugação de qualquer interesse privado. Em suas palavras,

o ente estatal poderia praticar condutas teoricamente contrárias às regras de direito concorrencial, abusar no preço dos insumos necessários a outras indústrias, exorbitar no exercício de sua dominância de mercado. Afinal, sendo mero vetor de consecução do interesse geral da coletividade, sua conduta não poderia ser refreada por interesses menores (porque privados) de natureza empresarial.

Essa cultura de intervenção, em nome do interesse público, significa um forte desincentivo à participação da iniciativa privada nesses mercados.

Majone (1999:20), por sua vez, reforça essa questão do risco regulatório aludindo a uma questão intrínseca à democracia majoritária.

A continuidade de políticas é notoriamente difícil de se conseguir numa democracia, que é uma forma de governo pro tempore. O limite de tempo imposto pela necessidade de eleições com intervalos regulares é um constrangimento forte que se impõe ao uso arbitrário, por parte dos vencedores das disputas eleitorais, dos poderes com que os investem os eleitores. No entanto, a segmentação do processo democrático, em períodos de tempo relativamente curtos, tem sérias conseqüências sempre que o problema enfrentado pela sociedade exigir soluções de longo prazo. $\mathrm{Na}$ expectativa da alternância, os políticos têm poucos incentivos para desenvolver políticas cujo sucesso, se houver, virá depois da próxima eleição. Assim, é difícil para os dirigentes políticos se comprometerem com credibilidade e com estratégias de longo prazo. O problema do comprometimento é ainda mais agravado pelo fato de, no processo de 
tomada coletiva de decisões, haver muitas maiorias possíveis cujas preferências respectivas não necessitam ser consistentes. Novamente, uma vez que os "direitos de propriedade política" são atenuados — uma legislatura não pode obrigar a sua subseqüente, e um governo não pode comprometer outro governo - as políticas públicas sempre são vulneráveis e renegadas, e conseqüentemente lhes falta credibilidade.

Ou seja, tornava-se assim fundamental, para o processo de privatização e para a atração de novos investimentos, sustentar uma nova perspectiva baseada na credibilidade política, imediata e intertemporal, do marco regulatório. É enfim essa busca de credibilidade que irá sustentar algumas dimensões normativas do arranjo institucional comum da maior parte das novas agências reguladoras independentes, conforme observa Melo (2001:256):

os dirigentes das agências possuem mandatos fixos, não coincidentes com o presidente da República, e estabilidade;

suas indicações, feitas pelo Executivo, precisam ser aprovadas pelo Legislativo;

口 as agências não são subordinadas hierarquicamente aos ministérios e constituem a última instância de recurso no âmbito administrativo;

口 possuem delegação normativa, poder de instruir e julgar processos e poder de arbitragem;

口 possuem orçamento e quadro de pessoal próprio.

Além da independência política e administrativa, ${ }^{4}$ outra característica essencial das ARIs são as altíssimas especialização e qualificação técnica exigidas de seu quadro de pessoal. Isto se torna extremamente necessário, se considerarmos a razão precípua da regulação econômica: a mitigação das falhas de mercado, ou seja, da incapacidade de alguns mercados alocarem eficientemente os recursos. Segundo Salgado (2003:2),

na presença de falhas, os mercados não fornecem sinais suficientes para garantir escolhas adequadas, que levem ao equilíbrio entre ofertantes e demandantes. O grande desafio para a regulamentação econômica é en-

\footnotetext{
${ }^{4}$ Cabe destacar que não é uma independência irrestrita. Os dirigentes são indicados pelo presidente da República e submetidos à aprovação do Senado. A independência é melhor entendida após esse processo, uma vez que o dirigente não pode ser removido, sem justa causa, do seu mandato.
} 
contrar o ponto ótimo que viabilize a lucratividade, de um lado (e, portanto, a operação e o investimento das empresas), e o bem-estar dos consumidores, de outro, na forma de disponibilidade de bens e serviços de qualidade e a preços razoáveis.

Ou seja, contrariamente ao argumento neoliberal que considera o livre-mercado uma panacéia ou mesmo a representação perfeita do interesse público, observa-se que somente em um ambiente de concorrência perfeita, condição notadamente irreal para muitos setores econômicos, o mercado conduz a um nível ótimo de eficiência alocativa. Dessa forma, um ambiente de concorrência imperfeita não prescinde da intervenção de instituições, como o Estado, para aumentar a eficiência alocativa desse mesmo mercado, e também para exercer, no caso de países como o Brasil, necessárias interferências redistributivas.

Ressalte-se que tais falhas de mercado são particularmente importantes nos setores econômicos recém-privatizados. A característica monopolista original de alguns deles confere um grande poder de mercado ao detentor de sua exploração, distorcendo potencialmente os preços do mercado e desincentivando o investimento de novos entrantes, dados a assimetria de informações, a incerteza e o longo prazo de retorno do mesmo. Se não bastasse, o mercado também pode gerar externalidades negativas, afetando a sociedade que está além da relação de consumo vendedor-comprador (Mankiw, 1999). Caberia assim ao novo ente regulador diminuir tais assimetrias, promover concorrência, diminuir os riscos dos investimentos e preservar o interesse público.

Para tanto as agências lançam mão de suas atribuições normativas, para o estabelecimento de regras e padrões; executivas, para a fiscalização e implementação de decisões administrativas; e judicantes, para o julgamento e a arbitragem de conflitos. Tais atribuições se concentram, basicamente, nas questões sobre preços, qualidade e condições de entrada e saída (Salgado, 2003:3). É dispensável dizer que tal missão demanda alta especialização e alta qualificação técnica das agências, em áreas como engenharia e economia, concentrando especialistas focados na regulação desses mercados complexos e imperfeitos, onde o custo de aquisição de informação é alto e o interesse público é potencialmente ameaçado.

Enfim, as agências reguladoras independentes teriam então, de forma simplificada, uma conformação institucional relativamente "blindada" da política e altamente especializada, em contraponto às burocracias mais generalistas dos ministérios. As agências deveriam ser capazes de controlar o desequilíbrio de informações do mercado, monitorar a qualidade e os pre- 
ços dos serviços públicos, garantir previsibilidade e sustentabilidade aos investimentos e à provisão dos serviços, incentivar a concorrência e implantar as políticas redistributivas formuladas pelo governo. Nos termos de Gomes (2003:7) cabe enfim às agências dar conta da regulação econômica, da regulação social e da regulação técnica ou de qualidade.

Para isso, é fundamental um correto desenho institucional interno e do ambiente em que se insere, que propicie relativa independência política, ante os governos, autonomia administrativa e orçamentária, e autoridade técnica em face do mercado e dos agentes regulados.

\section{A responsabilização das agências}

A questão da independência das agências, acima mencionada, ainda que constitua característica imprescindível ao sucesso do modelo de agências reguladoras independentes, constitui também um problema. $\mathrm{O}$ isolamento das agências das injunções políticas é considerado antidemocrático, assemelhando-se às opções ao estilo do autoritarismo tecnocrático. A sua relativa independência política poderia, por exemplo, impedir a flexibilização eventual dos contratos em nome do interesse público.

Como aponta Gomes (2003:7),

se uma face do sucesso do regime consiste na autonomia do ente regulador, a flexibilização dos mecanismos de atuação estatal em áreas tão essenciais de serviço público, com a ascensão de entes públicos com poderes quase-executivos, vez que implementam as políticas públicas setoriais; quase-judiciais, vez que julgam o comportamento das firmas de acordo com as normas definidas para o funcionamento da indústria, arbitram e intermedeiam conflitos entre firmas e entre firmas e consumidores, e suas decisões são irrecorríveis em outra instância administrativa; e quase-legislativos, vez que expedem normas e regulamentos em matérias de sua competência pode representar um ataque à concepção democrática tradicional refletida na noção de dicotomia entre política e burocracia estatal.

É então nesse contexto que se legitimam várias iniciativas visando ao controle das agências, como o Projeto de Lei Federal n⿳ํㅡ 3.337/2004, que defende o fortalecimento dos ministérios diante das agências, por meio de iniciativas que estabelecem a obrigatoriedade do contrato de gestão e a passagem das atribuições de outorga e concessão da agência para o ministério, ou mesmo o aprofundamento do controle social, ampliando as esferas de participação e mesmo 
propugnando a criação de ouvidorias. No caso do presente trabalho, no entanto, interessa o exercício do controle externo, sobre as agências federais, executado pelo Tribunal de Contas da União (TCU).

Antes porém de aprofundar esse ponto, cabe mencionar os atuais mecanismos de controle previstos no modelo institucional vigente das agências reguladoras independentes.

- Marcos regulatórios. As agências estão submetidas a marcos regulatórios que vão desde a própria Constituição Federal até legislações ou outros instrumentos legais mais específicos. Assim, ainda que permita alguma discricionariedade às agências, dado o caráter não-exaustivo desses "contratos formais", tais instituições constrangem a ação das agências, podendo contribuir para sua transparência e responsabilização.

- Indicação de dirigentes. Os diretores das agências são indicados pelo presidente da República e as indicações são submetidas à aprovação do Senado. Esse procedimento representa uma espécie de accountability ex ante, introduzindo um componente democrático na designação da direção das agências.

- Decisões colegiadas. As decisões da agência são tomadas de forma colegiada, após deliberação. Esse método dificulta a ocultação de informações privilegiadas ou a prevalência de um ou outro diretor eventualmente "capturado" por interesses privados, uma vez que o processo deliberativo contribui para tornar públicas as motivações que conduzem à determinada decisão.

- Explicitação das razões. Além do âmbito interno à diretoria, as decisões precisam ser justificadas e abertas, de forma ampla e detalhada, ao escrutínio público.

- Consultas públicas. Conforme determinações legais, várias decisões das agências precisam ser precedidas de consultas públicas.

- Foco inequívoco. O escopo especializado de ação das agências reguladoras facilita a responsabilização das agências, ao permitir o estabelecimento inequívoco da correspondência entre agente, ação e resultados.

- Judiciário. A presença dos marcos regulatórios e de relações contratuais no novo modelo de prestação de serviços públicos aumenta a importância do Judiciário como árbitro de conflitos, e também como supervisor ex post das próprias agências. O Ministério Público também tem um papel importante aqui, que culmina no encaminhamento de ações ao Judiciário ou mesmo nos termos de ajustamento de conduta. 
Ou seja, há uma série de procedimentos que, operando simultaneamente, contribuem para a legitimidade democrática das agências. Como coloca resumidamente Majone (1999:291):

\begin{abstract}
a legitimidade procedimental implica, entre outras coisas, que as agências são criadas por estatutos democraticamente promulgados que definem a autoridade legal e os objetivos das agências; que os reguladores são nomeados por funcionários eleitos; que a tomada de decisões em matéria reguladora obedece a regras formais que muitas vezes exigem a participação pública; finalmente, que as decisões das agências devem ser justificadas e estão abertas ao escrutínio judicial. O meio mais simples e básico de melhorar a transparência e a responsabilização das agências é exigir que os reguladores forneçam razões para suas decisões. Isto porque uma exigência de fornecimento de razões ativa um número de outros mecanismos para controlar a discrição reguladora, tais como o exame judicial, a participação e a deliberação públicas, o exame pelos pares, a análise de políticas para justificar prioridades reguladoras, e assim por diante.
\end{abstract}

\title{
Tribunal de Contas da União e avaliação de desempenho
}

Mas além dos mecanismos potenciais de responsabilização inerentes ao modelo de regulação, as agências reguladoras independentes, como "(...) qualquer pessoa física ou jurídica, pública ou privada, que utilize, arrecade, guarde, gerencie ou administre dinheiros, bens e valores públicos ou pelos quais a União responda, ou que, em nome desta, assuma obrigações de natureza pecuniária" (Constituição Federal, art. 70), deve submeter-se ao controle externo do Tribunal de Contas da União. Esse controle consiste em uma fiscalização de ordem contábil, financeira, orçamentária, operacional e patrimonial. Assim, tradicionalmente, seguindo os preceitos constitucionais, o Tribunal de Contas realiza sistematicamente auditorias de regularidade, conformidade ou ciclos anuais de checking the books, que observam as dimensões mencionadas, zelando pela legalidade no emprego do dinheiro público.

No entanto, na esteira dos preceitos da nova gestão pública, particularmente da gestão focada em resultados ou, mais precisamente, da busca de responsabilização dos administradores públicos tendo por base seu desempenho, o Tribunal de Contas da União, similarmente ao que vêm fazendo entidades "irmãs" em outros países como EUA (US General Accounting Office - GAO) ou Reino Unido (UK National Audit Office - NAO), ampliou seu escopo de atuação além das auditorias de regularidade. Como coloca Gomes (2003:1), 
o controle externo das privatizações e da regulação exercido pelo Tribunal de Contas da União (...) não se restringe à análise de conformidade e legalidade de procedimentos e atos administrativos, mas precipuamente a trabalhos de auditoria, análise, avaliação e revisão de práticas e procedimentos administrativos finalísticos de órgãos governamentais do poder executivo, notadamente entes reguladores e, quando cabível, de seus regulados com base no arcabouço jurídico e dos princípios do regime regulatório brasileiro, bem como de boas práticas de gestão regulatória, visando garantir que os processos de regulação e de privatização atinjam seus objetivos de forma econômica, eficiente e efetiva, em benefício da sociedade brasileira.

Para tanto, o Tribunal de Contas da União executa auditorias de desempenho ou de performance, definidas por Gomes (2003:13) como um

conjunto de procedimentos técnicos e métodos de investigação utilizados por instituições centrais de controle da administração pública para obtenção, processamento e disseminação de informações relevantes de revisão e avaliação de atividades, projetos, programas, políticas e órgãos governamentais quanto a aspectos de economia, eficiência e efetividade, boas práticas de gestão, eqüidade, alcance de metas, capacidade de gerenciamento de desempenho, informações de desempenho, entre outros critérios orientados para o resultado da atuação pública.

Essas auditorias são abrangentes e envolvem as seguintes dimensões, no âmbito das agências reguladoras, conforme Gomes (2003:13):

- economia regulatória - relacionada aos resultados obtidos com a privatização, licitação ou concessão dos serviços públicos, visando tanto maximizar os valores angariados pelo Estado quanto minimizar os custos a serem arcados pelos usuários;

- eficiência regulatória - representando a relação entre os custos e os produtos ou resultados da regulação, como os custos e resultados das fiscalizações ou mesmo a sinergia entre esferas governamentais de fiscalização;

- efetividade regulatória - grau com que os objetivos da regulação são alcançados e a relação entre os resultados desejados e os resultados reais da gestão regulatória;

- boa prática de gestão regulatória - avaliação dos sistemas de contabilização, planejamento, relação com os clientes, gestão de recursos humanos; 
- boa governança regulatória - avaliação das relações da agência com outras instituições, apurando a sinergia ou o grau de coordenação obtido quanto à política regulatória;

- qualidade de serviço avaliado segundo a satisfação do usuário, tanto em relação às agências quanto às concessionárias;

- atendimento de metas - extensão na qual a agência ou o concessionário atingiu as metas.

Tais auditorias são seguidas por avaliações colegiadas, no Tribunal de Contas da União e, como nas demais fiscalizações, uma vez constatada alguma irregularidade, o TCU pode aplicar as seguintes sanções (Brasil, 2005b):

口 multas;

- condenações para ressarcimento do prejuízo aos cofres públicos;

- decretação, por prazo não superior a um ano, da indisponibilidade de bens do responsável, tantos quantos considerados bastantes para garantir o ressarcimento dos danos em apuração;

- inabilitação, por período de cinco a oito anos, para o exercício de cargo em comissão ou função de confiança no âmbito da administração pública federal;

- declaração de inidoneidade do licitante fraudador para participar, por até cinco anos, de licitação na administração pública federal.

Além disso, quando o tribunal constata dano ao erário que decorra de ato de gestão ilegítimo ou antieconômico ou desfalque ou desvio de dinheiro, bens ou valores públicos, remete cópia da documentação ao Ministério Público da União para ajuizamento das ações cíveis e penais cabíveis, conforme prevê o art. 16, §3º̄ , da Lei nํㅡㄴ.443, de 1992.

Alguns exemplos dessas auditorias de desempenho nas agências e no mercado regulado são encontrados nos relatórios trimestrais de atividades do TCU. Podemos destacar, conforme Relatório de atividades $1^{0}$ trimestre de 2005, a auditoria na Aneel na qual o TCU questiona o enquadramento dado pela agência aos consumidores da chamada "subclasse residencial baixa renda" que, por lei, estariam isentos do pagamento dos encargos de contratação da capacidade emergencial, da aquisição de energia emergencial e da recomposição tarifária emergencial. 
$\mathrm{Na}$ auditoria realizada pelo tribunal em 2003 — apreciada no Acórdão n⿳0 344/2003 - Plenário, constatou-se a inadequação dos critérios de identificação dos consumidores de baixa renda, baseados no baixo consumo domiciliar de energia elétrica. Por meio de técnicas estatísticas, o TCU demonstrou a baixa correlação entre as variáveis "renda per capita" e "consumo domiciliar de energia".

Outro exemplo é apontado no Relatório de atividades $3^{0}$ trimestre de 2004, no qual

em auditoria realizada com o objetivo de verificar a adequação dos valores de pedágio na rodovia Rio-Teresópolis, o TCU detectou impropriedades nas revisões, alterações e adequações tarifárias. Caso seja refeito todo o fluxo de caixa da concessão e corrigidas as impropriedades verificadas, as tarifas apuradas pela auditoria apresentariam decréscimo de $4,7 \%$ e $6,7 \%$, para as praças principais e auxiliares de pedágio, respectivamente, em relação aos preços em vigor a partir de 20 de novembro de 2001. Foi determinada à Agência Nacional de Transportes Terrestres (ANTT) que adote as medidas necessárias para que a Concessionária Rio-Teresópolis S.A. - CRT corrija impropriedades no fluxo de caixa relativo às revisões de 1 a 9 e providencie a reversão ao referido fluxo, da receita de pedágio recebida indevidamente (TC n⿳0 006.931/2002-0, Acórdão no 988/Plenário, de 21 de julho de 2004).

Finalmente, um último exemplo refere-se à Anatel. Nesse caso, conforme Relatório de atividades $4^{\circ}$ trimestre de 2004 , o TCU procurou

analisar se as reformas regulatórias e a privatização do setor de telecomunicações efetivamente contribuíram para a ampliação e democratização do acesso aos serviços de telefonia, e avaliar o desempenho da agência no cumprimento das metas de universalização de acesso ao sistema fixo de telefonia comutado (STFC).

As conclusões do TCU são que as reformas no setor de telecomunicações foram positivas, apesar de parcela considerável da população brasileira ainda não possuir telefone particular (39,8\%, conforme dados do IBGE). Diante disso, o TCU determinou à Anatel a apresentação de um plano de reformulação dos processos de fiscalização das obrigações de universalização, explicitando as soluções e cronograma de implementação de ações para corrigir as falhas destacadas na auditoria (TC n⿳0 012.581/2003-3, Acórdão n⿳0 1.778/Plenário, de 10 de novembro de 2004). 
Enfim, há notadamente uma evolução na forma tradicional de atuação do Tribunal de Contas da União: às auditorias de regularidade do TCU, e em sintonia com a mudança de paradigma introduzida pela nova gestão pública, acrescentam-se as auditorias de performance. E essas auditorias são extremamente abrangentes, incidem sobre as agências, sobre os regulados e sobre o mercado, e avaliam até a efetividade da regulação.

\section{Agências e TCU: conflito institucional?}

Não se pretende aqui julgar, em termos substantivos, o novo escopo de atuação do Tribunal de Contas da União. Na verdade é fundamental, e até tardia, a preocupação do TCU com a medição do desempenho ou de dimensões como efetividade no uso dos recursos públicos. A questão que emerge, no entanto, refere-se à razoabilidade dessa complexa, se não concorrente, distribuição de competências. Não há um conflito entre as iniciativas de auditoria de desempenho do TCU e o modelo institucional de regulação por agências reguladoras independentes? Não estaria o TCU auditando dimensões próprias do escopo exclusivo das agências?

Para tecer considerações sobre essas questões é imperativo, antes de tudo, apontar a dúvida quanto à sustentação legal das auditorias de desempenho do TCU. Conforme consta em seus documentos, a ampliação de escopo do TCU é "legalmente" sustentada, baseando-se no inciso IV do art. 71: particularmente, na dimensão "operacional" da fiscalização prescrita pela Constituição de 1988. A partir de tal interpretação e de sua Lei Orgânica (Lei $n^{0}$ 8.443, de 16 de junho de 1992), o TCU emitiu a Instrução Normativa TCU no 27, de 7 de dezembro de 1998, que prescreve os procedimentos de auditoria. Conforme colocado por Gomes (2003:9),

tendo em vista as alterações institucionais decorrentes dos processos de privatização, o Tribunal de Contas da União, por meio de normativos internos, editou regulamentos que dispõem sobre a fiscalização dos processos de desestatização, concessão, permissão e autorização de serviços públicos. Essas normas prevêem o acompanhamento desses mecanismos de flexibilização do Estado tanto na fase do acompanhamento da outorga, emitindo parecer sobre a legalidade e economicidade desses processos, quanto na fase do acompanhamento da execução contratual, ou seja nos processos regulatórios decorrentes da flexibilização.

Ora, a interpretação dada ao termo "operacional", associando-o a resultados ou desempenho, é controversa. "Operacional" relaciona-se a procedi- 
mentos, a operações, a meios; não diretamente a fins. Reforça essa hipótese o fato de que, no contexto da Constituição de 1988, os preceitos da nova gestão pública não estavam sequer esboçados no Brasil. Pelo contrário, o ambiente presente na Constituinte era de completar a "revolução burocrática". Assim, não é possível afirmar que haveria um conflito de instituições, pelo menos do ponto de vista formal. Mas é possível sugerir que há uma extrapolação das atribuições do TCU.

Uma segunda consideração refere-se à capacidade técnica e independência política do Tribunal de Contas da União para proceder as auditorias. Como já visto, o modelo de regulação via agências reguladoras independentes não prescinde de uma certa "blindagem" política e de alta especialização dos reguladores, tendo em vista os objetivos de conferir previsibilidade aos mercados e, ao mesmo tempo, dialogar de forma altiva com os regulados.

Do ponto de vista político, convém lembrar que os conselheiros do TCU são designados à razão de $2 / 3$ pelo Congresso Nacional e $1 / 3$ pelo presidente da República, estes últimos após aprovação do Senado Federal. Além disso, a Câmara dos Deputados, o Senado Federal e as comissões técnicas ou de inquérito podem solicitar ao TCU a realização de auditorias e inspeções e o fornecimento de informações sobre fiscalizações realizadas, na forma do art. 71, incisos IV e VII, da Constituição Federal. Ou seja, o TCU pode ser significativamente suscetível à interferência política, até mesmo por meio do direcionamento de auditorias. Essa permeabilidade política, ausente nas agências, pode trazer instabilidade, tanto às agências quanto ao mercado regulado, comprometendo os esforços de prover um ambiente propício aos investimentos.

Em relação à especialização técnica, questiona-se a possibilidade de o TCU constituir equipes altamente profissionais e capacitadas para auditar as agências e o mercado nas dimensões previstas no amplo escopo das auditorias de desempenho. Um dos argumentos em prol do modelo de agências reguladoras é justamente o seu foco inequívoco, o que permite uma profunda especialização nos assuntos do mercado a ser regulado, diferenciando-se das burocracias mais generalistas, presentes nos ministérios. A menos que o TCU criasse equipes focadas somente em um setor regulado, certamente seu grau de especialização será menor que o das agências. Além disso, a constituição de equipes de auditores cada vez mais especialistas representa, consideradas as agências, uma sobreposição institucional com várias conseqüências do ponto de vista organizacional: desperdício de recursos públicos, duplo comando, imprevisibilidade da regulação, entre outras.

Enfim, as novas atribuições de auditoria de desempenho do TCU, embora essenciais, parecem conflitar com outra das criações da nova gestão pública: o modelo de regulação baseado em agências reguladoras independentes. Acre- 
dito ser necessário repensar um ou outro modelo, ou ambos, de tal forma que não haja uma sobreposição de funções, bem como se maximize a potencialidade das agências e do tribunal e que se crie uma ambiente de fato propício à atração de investimentos privados, tão caros nos dias de hoje.

\section{Referências bibliográficas}

ABRUCIO, F. L. La responsabilización (“accountability”) en la nueva gestión pública latinoamericana. In: CENTRO LATINOAMERICANO DE ADMINISTRACIÓN PARA EL DESARROLLO (CLAD). La responsabilización en la nueva gestión pública latinoamericana. Clad, set. de 2000 .

BRASIL. Casa Civil. Projeto de Lei Federal nº 3.337/2004 de 12 de abril de 2004a.

BRASIL. Tribunal de Contas da União (TCU). Relatório de atividades $3^{\underline{o}}$ trimestre de 2004. Brasília: TCU, Secretaria de Planejamento e Gestão, 2004b.

Relatório de atividades $4^{0}$ trimestre de 2004. Brasília: TCU, Secretaria de Planejamento e Gestão, 2005a.

Relatório de atividades $1^{\underline{Q}}$ trimestre de 2005. Brasília: TCU, Secretaria de Planejamento e Gestão, 2005b.

BRESSER-PEREIRA, L. C. Da administração pública burocrática à gerencial. Revista do Serviço Público, v. 47, n. 1, p. 7-29, 1996.

GOMES, M. B. O controle externo de agências reguladoras no Brasil em perspectiva comparativa: lições, eventos recentes e desafios futuros. In: CONGRESO INTERNACIONAL DEL CLAD SOBRE LA REFORMA DEL ESTADO Y DE LA ADMINISTRACIÓN PÚBLICA, 8. Anales... Panamá, out. 2003.

MAJONE, G. Do Estado positivo ao Estado regulador: causas e conseqüências de mudanças no modo de governança. Revista do Serviço Público, jan./mar. 1999.

MANKIW, N. G. Introdução à economia - princípios de micro e macroeconomia. Rio de Janeiro: Campus, 1999.

MARQUES NETO, F. de A. Agências reguladoras: instrumentos do fortalecimento do Estado. São Paulo: Abar, 2003.

MELO, M. A. A política da ação regulatória: responsabilização, credibilidade e delegação. Revista Brasileira de Ciências Sociais, v. 16, jun. 2001.

SALGADO, L. H. Agências regulatórias na experiência brasileira: um panorama do atual desenho institucional. Rio de Janeiro: Ipea, 2003.

RaP Rio de Janeiro 40(4):615-30, Jul./Ago. 2006 